\title{
Propaganda y publicidad comercial: un principio diferenciador
}

Antonio Pineda Cachero | apc@us.es

UNIVERSIDAD DE SEVILLA

Resumen: El objetivo de este artículo es establecer una distinción conceptual entre la propaganda y la publicidad comercial. Frente a los enfoques centrados en los formatos mediáticos, los procedimientos de comunicación o el contenido de los mensajes, la intención comunicativa se entiende como el criterio diferenciador entre propaganda y publicidad, de lo cual se derivan otras consecuencias. Los desarrollos históricos de la propaganda y la publicidad refuerzan la idea de que las causas de la publicidad no tienen el mismo carácter transhistórico que las de la propaganda. En cualquier caso, la publicidad puede reflejar contenidos ideológicos e incluso ser instrumentalizada propagandísticamente.

Palabras clave: teoría de la propaganda, teoría de la publicidad.

Abstract: This paper aims to establish a conceptual distinction between propaganda and advertising. In contrast with the perspectives centered on media formats, communication techniques, or message content, communicative intention is understood as the differentiating criterion with regard to propaganda and advertising. Other consequences are derived from this. The historical developments of propaganda and advertising reinforce the notion that advertising's causes lack the trans-historical quality of propaganda's causes. Anyway, advertising can mirror ideological contents, and even be propagandistically instrumentalized.

Key words: propaganda theory, advertising theory. 


\section{Introducción}

El objetivo de este artículo es establecer una distinción conceptual entre la propaganda y la publicidad comercial ${ }^{1}$. Bajo el término publicidad entenderemos en lo que sigue "publicidad comercial", al considerar que el carácter "comercial" de esta actividad de comunicación es conceptual e históricamente determinante en ella. En el ámbito de las Ciencias de la Información y la Comunicación suele también hablarse de "publicidad política", "publicidad institucional" o "publicidad social", pero se trata básicamente de derivaciones de la publicidad comercial en cuanto a los formatos utilizados o los procedimientos aplicados. Así, por ejemplo, la "publicidad política" es básicamente una extrapolación de los procedimientos (la simplificación, por ejemplo) y los formatos mediáticos (espots de televisión, por ejemplo) de la publicidad comercial al ámbito político. De hecho, el año que generalmente suele considerarse como fecha del nacimiento del marketing político, 1952, es también el primer año en que se utilizaron espots políticos en elecciones presidenciales, lo cual indica un vínculo histórico estrecho entre el marketing político y la publicidad política. Autores como Mario Herreros Arconada piensan que, debido sobre todo a la influencia estadounidense, "se denomina publicidad política a lo que, en rigor, debiera denominarse propaganda en formas publicitarias" (1989: 155). Como señala González Martín (1996: 8): "La publicidad es un arma mercadotécnica al servicio de las estrategias comerciales de las empresas, aunque cada vez es más empleada por partidos, gobiernos e instituciones". La idea de "arma mercadotécnica al servicio de las estrategias comerciales de las empresas" (en palabras de González Martín) es relevante para nuestra argumentación, pues apunta a la génesis del fenómeno, mientras que su uso político es una extrapolación procedimental y mediática del quehacer comercial.

Frente a la identificación que en ocasiones se establece entre publicidad y propaganda, la hipótesis que guía este artículo radica en que son dos fenómenos comunicativos diferenciables. En un trabajo anterior (Pineda Cachero, 2006) establecimos bases conceptuales y definitorias para acotar la esencia comunicacional de la propaganda; en el presente trabajo pretendemos (a partir del marco teórico del trabajo citado) aplicar la misma lógica diferenciadora a las relaciones entre propaganda y publicidad. Partimos, por lo tanto, de que la propaganda posee unas propiedades esenciales que nos permiten diferenciarla -en cuanto fenómeno comunicativo- de la publicidad. En definitiva, la óptica que adoptamos implica un análisis de la publicidad comercial desde la teoría de la propaganda.

No estamos de acuerdo con la idea de que "la separación maniquea entre propaganda y publicidad vuelve a encerrar nuevos intereses que esconden las intenciones de los grandes

\footnotetext{
${ }^{1}$ Por supuesto, la idea de diferenciar ambos fenómenos no es nueva. Para un examen de las relaciones y diferencias entre propaganda y publicidad, véase Herreros Arconada, 1989: 86-95. Este autor sintetiza en un cuadro las diferencias y analogías entre publicidad y propaganda (Herreros Arconada, 1989: 95). Para las semejanzas y diferencias entre propaganda y publicidad, véase asimismo Musitu y Castillo, 1982: 22-26; Vázquez y Aldea, 1991: 41-42; Reyzábal, 1999: 69-77; Fernández Souto, 2006. Para diferencias "técnicas o de procedimiento" entre la publicidad política (del tipo más mercadotécnico) y la comercial, véase Qualter, 1994: 192-195.
} 
núcleos de poder" (Veres Cortés, 1999: 140). Por el contrario, creemos que la intención de distinguir ambos fenómenos no se debe necesariamente al sometimiento al poder. Nuestro interés es científico: intentar separar lo que a nuestro juicio son fenómenos distintos en el contexto de las Ciencias de la Información y la Comunicación².

\section{Más allá de la identificación terminológica y conceptual}

Comenzaremos con un ejemplo de la confusión terminológica y conceptual que suele caracterizar las reflexiones sobre propaganda y publicidad. En el Tratado completo de publicidad y propaganda, de 1935, Rafael Bori y José Gardó consideran que la palabra "Propaganda" es la "expresión vulgar y corriente" de la publicidad comercial, en un contexto donde esta última comienza a desarrollarse y consolidarse científicamente (1935: XX). La analogía "propaganda = publicidad" pervive aún hoy en el lenguaje popular; sobre todo en los países de habla hispana. De hecho, a través del libro citado, que versa básicamente sobre publicidad, los autores utilizan publicidad y propaganda indistintamente.

Aunque históricamente la propaganda precede a la publicidad, los autores citados hablan, curiosamente, de la historia de la publicidad y su "génesis misma [en] la historia" (Bori y Gardó, 1935: 20) con ejemplos que, sin embargo, tienen un cierto cariz propagandístico: las pirámides de Egipto, las leyendas, los actos heroicos, “la suntuosidad de las edificaciones religiosas" o "los alminares de las mezquitas, los más eficaces propagadores de la guerra santa". "En otro orden de ideas, el negociante necesitó que fuese conocido su comercio, que alcanzara renombre su establecimiento para que afluyera a él el público y adquiriese los géneros en venta, realizando con ello un beneficio, y recurrió a la Publicidad" (Bori y Gardó, 1935: 21).

Se trata de un punto de vista bastante recurrente en las consideraciones sobre propaganda y publicidad; un punto de vista según el cual la publicidad sería una mera aplicación técnica de la propaganda a fines comerciales. Por supuesto, lo que hay detrás de la visión histórica de Bori y Gardó es la indiferenciación entre propaganda y publicidad. Este es el tipo de identificaciones conceptuales que pretendemos discutir, pues, desde nuestra perspectiva, la propaganda no es algo meramente procedimental a lo que se pueda recurrir, sino un fenómeno generado en función de unas determinadas circunstancias y para unos fines determinados. Esas circunstancias y fines demuestran ser universales en la historia humana, y no dependen en absoluto de factores técnicos, sino de elementos como el poder y la ideología (Pineda Cachero, 2006).

Desde un punto de vista terminológico, la publicidad ha sido denominada por un elevado número de autores "propaganda comercial", pero consideramos que se trata de un fenómeno distinto y, como tal, es apropiado reservarle un nombre también distinto. El término inglés

\footnotetext{
${ }^{2}$ Quiero expresar mi agradecimiento a Jorge David Fernández Gómez, Juan Carlos Rodríguez Centeno y David Selva Ruiz, profesores del Departamento de Comunicación Audiovisual y Publicidad y Literatura de la Universidad de Sevilla, por las sugerencias y comentarios realizados acerca de este trabajo.
} 
advertising, o, en castellano, publicidad comercial (para diferenciarla de "publicidad" en un sentido amplio) son algunas de las posibilidades existentes. Por ello, consideramos que también debe rehuirse la identificación terminológica entre ambos fenómenos; máxime cuando desde el punto de vista etimológico también podrían encontrarse diferencias entre "propaganda" y "publicidad" 3 .

En definitiva, la tendencia a considerar la propaganda y la publicidad como fenómenos indistinguibles no es nueva. Desde el punto de vista conceptual, propaganda y publicidad se han visto como fenómenos convergentes hasta la confusión (González Lobo, 1998: 55-56) o con límites de diferenciación poco claros (García Uceda, 1997: 20); asimismo, sus diferencias se han diluido en un "discurso publipropagandístico" (Vázquez y Aldea, 1991: 40-46). También se han realizado identificaciones entre ambos fenómenos, como en el caso de algunos autores de la tradición funcionalista. En el libro Propaganda and Promotional Activities. An Annotated Bibliography, la publicidad comercial equivale a propaganda - por ejemplo, en el apartado sobre bibliografía de "Evaluaciones generales de la Propaganda", hay decenas de títulos sobre advertising (Lasswell, Casey y Smith, 1969: 373-377)-; y en Public Opinion and Propaganda, Leonard W. Doob identifica "advertisement" como "propaganda" (1966: 251). Por otro lado, también se ha visto la publicidad (desde una perspectiva crítica) como un componente de un sistema propagandístico (como es el caso de Chomsky Cogswell, 1997: 1-2-), o bien se han eliminado las diferencias entre ambas: Horkheimer y Adorno (también desde un punto de vista crítico) dan a entender que la publicidad comercial y la propaganda - concretamente, la nazi- son lo mismo (1998: 208, 204). I gualmente, se ha visto, de manera más o menos explícita, la publicidad como una forma de propaganda (J owett, 1987).

Nuestra postura se separa de estas tendencias (funcionalistas, críticas, etc.) a la indiferenciación. Al partir de la hipótesis teórica de que propaganda y publicidad son fenómenos distintos, habrá que mostrar el principio por el cual se diferencian. Para ello, repasaremos algunos criterios o enfoques desde los cuales podrían relacionarse ambos fenómenos.

\section{El enfoque formal: la publicidad como continente sin contenido}

Algunas definiciones de la publicidad tienen un carácter excesivamente formal que puede ocasionar confusiones con la propaganda, al no atribuírsele a la publicidad un contenido específico.

Por ejemplo, Bernays entendía por publicidad, en tanto que medio disponible para las relaciones públicas, "cualquier espacio pagado disponible como vehículo de un mensaje"

\footnotetext{
3 Para un análisis de los orígenes etimológicos de los términos "publicidad" y "propaganda", véase el artículo de Alfonso Méndiz Noguero publicado en este mismo número de Questiones Publicitarias. Para las diferencias etimológicas entre "propaganda" y "publicidad", véase además Durandin, 1990: 13, nota 2; Pineda Cachero, 2006: 27-30.
} 
(1998: 119). Se trata de una diferencia fundamental con la propaganda: desde este punto de vista, la publicidad sería un continente, abierto a contenidos políticos, religiosos, comerciales, publirrelacionistas, institucionales, etc; la propaganda, por el contrario, tendría un contenido concreto (siempre subordinado a fines de poder). La definición de Bernays, a pesar de ser excesivamente formal, posee un elemento diferenciador importante: la publicidad sería una comunicación pagada, lo cual no necesariamente sucede con la propaganda. En determinados sistemas, una instancia de poder puede comprar espacio mediático y anunciar su ideología, pero si la ideología de esa instancia de poder es propagada mediante productos de la cultura de masas, por ejemplo, es posible que dicha instancia de poder acabe incluso ganando dinero con tales productos. Así, el propagandista puede financiar un producto de entretenimiento que circule comercialmente, y, junto a los potenciales beneficios ideológicos, podría incluso recibir beneficios económicos.

El punto de vista formal no ha sido expuesto sólo por Bernays. Considérese la definición de "advertising" que da la American Marketing Association en su Dictionary of Marketing Terms: "The placement of announcements and persuasive messages in time or space purchased in any of the mass media by business firms, nonprofit organizations, government agencies, and individuals who seek to inform and/or persuade members of a particular target market or audience about their products, services, organizations, or ideas"4 . Esta definición gira sobre todo en torno al elemento mediático ("time or space purchased in any of the mass media..."), y engloba una serie de contenidos que trascienden los límites comerciales de la publicidad. Algo parecido ocurre con la definición de publicidad ofrecida por Enrique Ortega en La comunicación publicitaria: “Proceso de comunicación de carácter impersonal y controlado que, a través de medios masivos, pretende dar a conocer un producto, servicio, idea o institución con objeto de informar o de influir en su compra o aceptación" (1997: 22). Se trata de una definición amplia de publicidad, que englobaría también a la publicidad institucional y a ciertos tipos de propaganda. Según Ortega, "la publicidad se utiliza cada día más para dar a conocer ideas de diversa naturaleza, por ejemplo, políticas, religiosas, etc., así como en el ámbito de las organizaciones no lucrativas como la Cruz Roja, Unicef, etc., y en el ámbito de las instituciones públicas, como es el caso de ministerios, comunidades autónomas y ayuntamientos" (1997: 23) ${ }^{5}$. La siguiente definición, de William Wells, John Burnett y Sandra Moriarty, también es formal: “La publicidad es comunicación impersonal pagada por un anunciante identificado que usa los medios de comunicación con el fin de persuadir a una audiencia, o influir en ella" (1996: 12).

\footnotetext{
${ }^{4}$ American Marketing Association, Dictionary of Marketing Terms, "advertising". Disponible en Internet (14.11.2003): http://www. marketingpower.com/live/mg-dictionary-view.php?TID=69

${ }^{5}$ Por otro lado, para Ortega el fin de la publicidad no es necesariamente vender, dado que las campañas de organizaciones sin fines lucrativos y de las administraciones públicas no suelen relacionarse con objetivos de venta (1997: 37-38). Por ello, este autor señala que "el fin genérico de la publicidad, con independencia de la entidad que la realice, es el de conseguir que el público al que va destinada responda favorablemente al contenido del mensaje" (Ortega, 1997: 41). Esta concepción formal de la publicidad englobaría incluso al fenómeno propagandístico. Sin embargo, la de Ortega no es una definición completamente aplicable al fenómeno propagandístico dada la referencia a los "medios masivos", ya que la propaganda puede utilizar medios no masivos.
} 
La definición de la American Marketing Association implicaría para la publicidad contenidos que van más allá de lo comercial. Desde cierto punto de vista, la publicidad puede entenderse como un catálogo de formatos mediáticos disponibles para la inserción de mensajes regidos por distintos principios intencionales y que apelan a distintas áreas de la realidad. Así, la cuña radiofónica, el espot televisivo, o el banner en Internet, serían ejemplos de formatos publicitarios. Esta es una idea básica del enfoque formal.

Desde dicho enfoque, la publicidad consistiría elementalmente en un continente sin contenido: un conjunto de formatos disponibles para su utilización con contenidos diversos. Dado que la ideología puede ser uno de los contenidos posibles de los continentes publicitarios, desde el punto de vista formal las diferencias teóricas entre propaganda y publicidad serían irrelevantes. Si la consideramos como un medio potencialmente instrumentalizable al servicio de cualquier contenido comunicativo, la publicidad pierde substancia.

\section{El enfoque procedimental: la publicidad como "técnica"}

Si se contempla como una "técnica" o conjunto de "técnicas" (o, como preferimos nosotros, un conjunto de procedimientos), la publicidad adquiere algo más de substancia que la que poseería desde el punto de vista formal. No obstante, lo procedimental tampoco sería un principio diferenciador respecto a la propaganda.

El enfoque procedimental implica considerar la publicidad, no como un catálogo de formatos, sino como un catálogo de métodos y recursos de comunicación. Es decir, habría que tener en cuenta el carácter "técnico" o procedimental de la publicidad comercial. Este carácter procedimental podría inferirse de la siguiente idea de Haas (1966: 11):

\footnotetext{
La ciencia publicitaria tiene por objeto el estudio de los procedimientos más adecuados para la divulgación de ciertas ideas o para establecer relaciones de orden económico entre individuos en situación de ofrecer mercancías o servicios y otros susceptibles de hacer uso de tales mercancías o servicios. La técnica publicitaria aplica uno o varios de estos procedimientos con fines comerciales o desinteresados.
}

Aunque entre el fenómeno propagandístico y el publicitario existirían diferencias técnicas (Qualter, 1994: 192-195), las distinciones procedimentales no sirven como principio diferenciador, por la sencilla razón de que las "técnicas" de comunicación son elementos transferibles, que pueden trasladarse de una forma de comunicación a otra. Por ejemplo, es común afirmar que la simplificación es una técnica o regla operacional propagandística, pero lo mismo podría decirse de la publicidad comercial. Por citar una de las reglas de propaganda de Domenach (1986), la “orquestación” o repetición orquestada del mismo mensaje, encontramos que se trata de un procedimiento empleado también en campañas de imagen y relaciones públicas. Un recurso psicológico como la utilización de un comunicador "creíble" no dice nada sobre la esencia de la propaganda (o de la publicidad), pues es un procedimiento que se puede usar en otras formas de comunicación. 
Así, la consideración de la publicidad como un catálogo de procedimientos no supone un modo claro de diferenciarla de la propaganda, puesto que los recursos y métodos de comunicación son transferibles. La única diferencia estaría en que los procedimientos de comunicación A, B o C se utilizan, bien para difundir una ideología de poder, o bien para construir una marca comercial. Pero también es posible que el procedimiento B sea útil para una comunicación con fines sociales, o que el procedimiento A se muestre eficaz desde el punto de vista de la información periodística.

En definitiva, los procedimientos de comunicación no implican un principio diferenciador entre distintos fenómenos, dado que comparten con los formatos mediáticos (véase el apartado 3.) la relatividad desde el punto de vista de los fines y contenidos de la comunicación. De hecho, si propaganda y publicidad se contemplan desde el punto de vista de los procedimientos usados, no es raro que se vean como fenómenos unidos e indistinguibles (Veres Cortés, 1999). Como bien han señalado Musitu y Castillo (1982: 21): “Entre publicidad y propaganda las diferencias son más conceptuales que operativas".

\section{El enfoque desde el contenido: un criterio problemático}

Frente a la idea de la publicidad como continente sin contenido, podría proponerse que el contenido de la publicidad es genuinamente comercial, y que el contenido de la propaganda es ideológico. De este modo, hay autores que caracterizan a la publicidad como poseedora de un contenido comercial (González Lobo, 1998: 13-16, 33; Herreros Arconada, 1999: 448450). Eso implicaría, en teoría, un criterio diferenciador claro respecto a la propaganda, pero consideramos que los inconvenientes teóricos superan a las ventajas que ofrece el criterio del contenido.

Tales inconvenientes pueden encontrarse en relación a los dos fenómenos estudiados. En la propaganda, la cuestión de un contenido ideológico sólido es problemática (Pineda Cachero, 2006: 193-220); y, por el lado de la publicidad, se ha señalado que ésta puede ser vehículo de ideas. Así, el publicista Fernando Ocaña observa que "[n]uestra única función es vender. No sólo productos, sino también, por ejemplo, ideas" (2005: 26), y Juan Carlos Rodríguez Centeno aventura que "la publicidad, sin perder su finalidad comercial y en casos extremos, es un excelente medio para la difusión de contenidos políticos, es decir ideologías y símbolos" (2002: 128).

Obviamente, el contenido de la propaganda tenderá a ser más ideológico que el de la publicidad, pero nociones como la de que las marcas se convierten en ideología (Garrido, 2002) ponen en una tesitura difícil las ecuaciones del tipo "publicidad = contenido comercial" y "propaganda = contenido ideológico". La publicidad de marcas como Nike puede en ocasiones poseer más contenido ideológico que algunos mensajes considerados propagandísticos. En consecuencia, proponemos rechazar el criterio del contenido (ideológico versus comercial) como principio distintivo entre propaganda y publicidad. 


\section{El enfoque intencional como principio diferenciador}

Por supuesto, al afrontar las relaciones entre propaganda y publicidad puede optarse por los enfoques vistos en los apartados anteriores; y es incluso posible que algunas de tales aproximaciones puedan ser las preferibles desde el punto de vista profesional.

Nuestros objetivos son teóricos, y, en tal contexto, proponemos que el componente de la publicidad que puede servir como elemento diferenciador respecto a la propaganda es el relativo a la intención comunicativa, que en el caso de la publicidad sería básicamente de tipo comercial, y en el de la propaganda sería una intención ideológica al servicio del poder. En este sentido, nos separamos de la idea de la publicidad como poseedora de un "contenido" comercial, y lo sustituimos por una "intención" comercial. La perspectiva intencional, en este contexto, evita el problema de centrar la definición en el contenido de la comunicación. Como ocurre con la propaganda, lo importante de la publicidad no es lo que porta, sino hacia dónde quiere llegar. Nuestro punto de partida teórico es que lo propagandístico adquiere su propio status en razón de sus objetivos y del porqué de su existencia, y ello es precisamente lo que distingue al fenómeno de la propaganda de la comunicación publicitaria. La diferencia radica en las condiciones de generación de la propaganda, y no en elementos más superficiales y epifenoménicos.

De este modo, y al igual que existen individuos e instituciones que pretenden obtener poder sobre la sociedad mediante la comunicación (propagandística), existen individuos e instituciones que pretenden obtener beneficios económicos mediante la comunicación (publicitaria). Por supuesto, el criterio intencional no anula las posibles similitudes entre propaganda y publicidad; por ejemplo, es evidente que ambas tienen elementos procedimentales en común. Pero tales similitudes no son suficientes para distinguir los tipos de comunicación que estudiamos. Con razón ha apuntado Giacomo Sani (1983: 1333) que los nexos de la propaganda con la publicidad y las relaciones públicas se establecen a nivel de profesionales, técnicas o canales; al fin y al cabo, todas son formas de comunicación, pero sus propósitos son muy diferentes.

La publicidad y la propaganda comparten el intento de influir en favor del interés del emisor, pero esta naturaleza interesada está guiada por motivaciones distintas según sea el tipo de comunicación. Lo importante es por qué quieren influir la propaganda y la publicidad. Domenach, aún considerando la publicidad como una de las fuentes básicas de la propaganda (junto a la ideología política), en tanto en cuanto la provee de técnicas, eslóganes y una tendencia a la sugestión más que a la información, establece una distinción fundamental: la propaganda tiene un fin político; la publicidad, un fin comercial (1986: 8). Tal es la principal diferencia que Terence $H$. Qualter ve entre publicidad política y publicidad comercial: el tipo de conducta que se busca influir. La diferencia básica de que la publicidad persigue incrementar las ventas y la propaganda tiene fines ideológicos y políticos ha sido señalada por varios autores: Reboul, Domenach, etc. (Herreros Arconada, 1989: 87-92). Según María Victoria Reyzábal: "la distinción más significativa entre publicidad y propaganda 
debe centrarse fundamentalmente en sus objetivos o intención comunicativa. En función de tal criterio, no existen razones para utilizar como sinónimos ambos términos" (1999: 73). Musitu y Castillo (1982: 24) también establecen una diferencia en función del objetivo seguido. En definitiva, podría decirse que la diferencia crucial está en relación al objeto que persiguen propaganda y publicidad.

En el caso de la publicidad, no es la primera vez que se señala la importancia de los fines pecuniarios: “La publicidad se creó para ganar más dinero”, escribe Raúl Eguizábal Maza en Historia de la publicidad, “y no simplemente para vender más [...]. Es decir, la publicidad se creó con el fin de hacer que un producto más caro fuese más deseable que otro más barato y básicamente igual" (1998: 12). Así, la publicidad ha sido vista como un fenómeno con fines de venta y beneficio (Chapman Brown, 1929: 39-40). Según Rafael Esteve, presidente de la filial en España de la agencia de publicidad Young \& Rubicam: “Los anunciantes piden lo que siempre han pedido: vender" ${ }^{6}$. En España, la Ley General de Publicidad de 1988 entiende por “Publicidad: Toda forma de comunicación realizada por una persona física o jurídica, pública o privada, en el ejercicio de una actividad comercial, industrial, artesanal o profesional, con el fin de promover de forma directa o indirecta la contratación de bienes muebles o inmuebles, servicios, derechos y obligaciones"7.

Otras definiciones de publicidad se centran en el Receptor entendido como consumidor, lo cual puede relacionarse también con la idea del fin económico de la publicidad: si la propaganda se dirige al ser humano en tanto que sujeto con unas determinadas actitudes hacia el poder y la estructura social, la publicidad se dirige al ser humano en tanto que sujeto con unas determinadas actitudes hacia el universo de las marcas, los productos y los servicios comerciales. Según afirma Luis Bassat en El libro rojo de la publicidad: "La publicidad es... el arte de convencer consumidores" (2004: 33). Bassat (2004: 44) incide en la finalidad comercial de la publicidad: “El objetivo número uno de la publicidad es vender, conseguir resultados a corto plazo. Lo primero que debe conseguir la campaña es que el consumidor se dirija al comercio y compre. Pero hay algo más: la publicidad debe vender hoy y ser capaz de contribuir a construir una marca para el mañana".

Todo ello (derivado, insistimos, de la cuestión intencional) implica una distinción importante en cuanto al receptor de la comunicación, ya que los tipos de receptor que entran en el campo de la intención propagandística pueden ser muy variados: un votante (propaganda electoral), un soldado (propaganda bélica), un creyente (propaganda religiosa), etc. Es decir, los radios de acción de los emisores de propaganda pueden ser variados; sin embargo, el radio de acción de los emisores de publicidad se halla restringido al campo económicocomercial. Aunque una empresa se relacione publicitariamente con públicos muy distintos (y no sólo consumidores), el espectro de las comunicaciones que genere estará básicamente circunscrito a lo económico. La propaganda se dirige al receptor como ente político, o

\footnotetext{
${ }^{6}$ Rafael Esteve, en Modesto García, “Rafael Esteve, presidente de Young \& Rubicam. «La creatividad española ha llegado a su madurez»", ABCdario de la publicidad, 23 octubre 2007, p. 39.

${ }^{7}$ Ley 34/1988, de 11 de noviembre, General de Publicidad, Título Primero, Art. 2.
} 
religioso, o militar, o sociocultural, o incluso económico; para la publicidad comercial, el receptor es un sujeto de transacciones mercantiles.

Así, las diferencias entre propaganda y publicidad en lo relativo al Receptor pueden derivarse también de las diferencias intencionales entre ambos fenómenos. La publicidad y la propaganda comparten una visión antropológica y psicológica del receptor parecida, pero lo que quieren hacer con ese receptor es muy distinto.

La diferenciación mediante la intención comunicativa tiene otras implicaciones. La propaganda es un universal de la comunicación social humana en función de las cuestiones que trata (o, más exactamente, que están en juego): el modo de pensamiento del ser humano sobre su existencia política, el poder, el modo de organizar la sociedad, etc. Y la relevancia de estas cuestiones implica una diferencia importante con la publicidad comercial, que suele caracterizarse (en general) por una mayor banalidad. En realidad, esta trascendencia superior de la propaganda es una consecuencia de una de las condiciones de generación del fenómeno: la naturaleza socialmente macroestructural de los objetivos que persigue la propaganda (Pineda Cachero, 2006: 87-97; 133-135). Roger Mucchielli señala que, mientras que los comportamientos que persigue la publicidad no son demasiado importantes, los de la propaganda implican acciones trascendentes (citado en Herreros Arconada, 1989: 88). Guy Durandin (1990: 184) ha señalado que la propaganda "por lo general trata sobre problemas más importantes que la publicidad". Qualter destaca la importante diferencia que estriba entre elegir un producto y elegir un político, pues lo último "puede cambiar drásticamente el tejido social sin esperanza de corrección para una generación o más" (1994: 191).

Así, el factor intencional se imbrica con los efectos que se pretenden conseguir. La intención de la propaganda -que es ideológica y pro-poder- se relaciona con las esferas del pensamiento y la conducta que pretenden ser afectadas: las creencias religiosas, la forma de vida política, el sistema económico, etc. En cambio, la intención de la publicidad comercial intención que no es ideológica- se relaciona con esferas del pensamiento y la conducta menos trascendentes para la estructura social. Esto no equivale a decir que los contenidos de la publicidad no puedan ser socialmente trascendentes, sino que su intención no es tan trascendente como la de la propaganda.

La propaganda es un fenómeno comunicativo que trabaja para diseñar de manera externa marcos ideológicos generales, macroestructurales; la publicidad trabaja de manera interna en un marco ideológico determinado. En el caso de los sistemas capitalistas, la propaganda es la que se encarga de crear, mantener y/o reforzar el marco ideológico capitalista, mientras la publicidad desarrolla sus fines comerciales dentro de dicho marco. Confundirlas en este sentido es confundir dos tipos de comunicación con implicaciones muy distintas respecto al marco ideológico de las sociedades. Confundir la publicidad comercial con la propaganda equivaldría a confundir las personas que habitan un edificio con el arquitecto que 
ha diseñado dicho edificio: lo que hacen las primeras es operar en el marco que el segundo establece. Según Musitu y Castillo (1982: 24-25):

La publicidad en cuanto está vinculada al conjunto del sistema de la sociedad de consumo, ha sido acusada[...] de engendrar un estado de ánimo general en el que se pierden la introdeterminación y la voluntad de cambio político. Pero es discutible el que este efecto haya sido la intención de los fabricantes únicamente preocupados por vender sus productos contra los de la competencia. Si este efecto existe, es por causa del contorno general, el de la sociedad de economía liberal competitiva.

Consideramos que no puede menospreciarse la posibilidad de que "los fabricantes" hayan tenido una cierta "intención" política; no obstante, en el caso de que esa intención haya existido, se trataría de una intención propagandística, no publicitaria: una intención que va mucho más allá de "vender sus productos contra los de la competencia". De la cita anterior se extrae una idea importante: la publicidad puede existir en un determinado sistema (en este caso, el "contorno general" de "la sociedad de economía liberal competitiva") sin que en su intención generadora esté la propaganda de ese sistema.

En este contexto, es importante tener en cuenta que en el caso de la publicidad hallamos unas diferencias de grado enormes en los objetivos de poder que - de ser ciertas las teorías que identifican publicidad y propaganda- unificarían a los emisores. Tales diferencias van desde la pequeña tienda urbana que hace publicidad con pocos recursos para vender sus productos hasta la empresa multinacional que hace publicidad con grandes recursos para incrementar sus ventas y hacerse con un mercado que puede tener dimensiones planetarias. Es absurdo pensar que existe algún tipo de objetivo de poder que, como variable común, unificase a estos dos ejemplos de publicidad comercial, al igual que es absurdo pensar que el "poder" del que dispone una madre para lograr que sus hijos se comporten bien en la mesa es el mismo que el que tiene un partido político al frente del gobierno de un estado. En consecuencia, ¿participa del fenómeno propagandístico la octavilla publicitaria que pueda financiar la pequeña tienda urbana, en la misma medida que otras acciones a escala planetaria que sirven para implantar la ideología capitalista? Si se nos permite la ironía, es posible que el pequeño comerciante urbano que hemos imaginado se esté planteando, al financiar su octavilla, reforzar el capitalismo internacional y el poder planetario del nexo empresa-estado, dado que, en un sentido técnico, está haciendo "publicidad". Pero es más racional pensar que, simplemente, ese pequeño comerciante se está planteando aumentar las ventas de su negocio. Más aún, es incluso probable que ese pequeño comerciante rechace ideológicamente determinados fenómenos del capitalismo transnacional, tales como las empresas multinacionales, pues de hecho pueden suponer una amenaza competitiva para su pequeño negocio.

\section{La instrumentalización propagandística de la publicidad}

A nuestro criterio diferenciador podría objetarse que, aunque los emisores de publicidad no persigan deliberadamente el poder en el sentido en que lo persiguen los emisores de 
propaganda, la publicidad puede incrementar el poder económico de ciertas empresas y, por consiguiente, favorecer el dominio de ciertos grupos sobre la sociedad.

Este contraargumento nos parece rechazable por dos razones. En primer lugar, por la perspectiva que hemos adoptado, centrada en la intención del emisor, y no en los efectos del mensaje. En segundo lugar, porque el objetivo económico empresarial carece, en el caso de la publicidad, de las implicaciones macroestructurales del mensaje propagandístico.

Esta segunda razón es relevante para nuestra argumentación. Es evidente que la búsqueda de beneficios y objetivos económicos puede redundar en última instancia en el incremento del poder entre los sujetos más poderosos de una sociedad determinada. Pero la publicidad comercial suele carecer de otro elemento fundamental en la propaganda: la referencia a un sistema o una ideología generales y tendentes al poder. El referente o beneficiario de la publicidad no suele ir más allá de una empresa privada aislada, sin planteamientos ulteriores sobre la auténtica estructura de poder que sirve de marco a esas empresas aisladas en las democracias capitalistas occidentales. La influencia sobre tal tipo de estructuras de poder sería el campo de actuación de la comunicación propagandística.

Ahora bien, en el caso de que la industria de la publicidad se considere como un integrante generador de ese tipo de estructuras de poder, y puedan verificarse objetivos ideológicos de poder, podrá entenderse como parte de un esfuerzo propagandístico. Como afirmó Tom Sutton, vicepresidente ejecutivo internacional de J. Walter Thompson:

Pienso que las organizaciones internacionales como la Asociación Internacional de la Publicidad y la Cámara de Comercio Internacional tienen la misión de predicar el evangelio de la libertad, y de cuidar que en aquellos casos en los que deba haber sistemas de control y contención se exporten al extranjero los mejores de esos sistemas, y no los peores (citado en Schiller, 1987: 182).

En casos como éste - sin descender al análisis de textos publicitarios concretos que pueden no depender de tales principios rectores- sería perfectamente válido hablar de un fenómeno propagandístico, canalizado por organizaciones publicitarias y empresariales y con fines evidentemente ideológicos ("el evangelio de la libertad").

Pero es posible que este tipo de propaganda canalizada por una organización publicitaria sea un fenómeno poco usual. Más común sería otra posibilidad en las relaciones publicidadideología: la adecuación de los anuncios a la ideología predominante, fenómeno por el cual la publicidad actuaría como un reflejo ideológico. Este reflejo puede verse de manera más explícita en los regímenes totalitarios, como el del fascismo:

En total armonía con la publicidad del régimen encontramos a la publicidad industrial: "Fieles al trabajo con honor", incita una colosal águila romana en nombre de los establecimientos milaneses de la Alfa Romeo, a la vez que, igualmente sacada del bestiario lictorio, la loba capitolina anuncia, para la Bomprini Parodi Delfino, tanto pacíficos fertilizantes para la agricultura como municiones y explosivos para la guerra, magnífico aprovechamiento práctico del principio mussoliniano antes recordado según el cual "el arado es el que traza el surco, pero la espada quien lo defiende"; y las acererías matan dos pájaros de un tiro. También Italia es 
para los industriales un espléndido símbolo de promoción de ventas: la gasolina Victoria es "La gasolina de los italianos"; los pequeños camisas negras y las simpáticas italianitas de su edad juegan a tirar de la cuerda con Sniafiocco y Lanital, "los productos textiles de la independencia" de la marca Snia Viscosa; una rutilante diosa Roma monta guardia en los establecimientos de la Italviscosa. No se olvida el mar, "Mare Nostrum", por parte de la Odeto Terni Orlando (por si alguien quería hacer provisión de acorazados), ni el cielo (Magneti Marelli) en el que "la perfección del producto es un auxilio seguro para la potencia de las alas fascistas" (Pignotti, 1976: 112).

Es lógico que la publicidad refleje la ideología del contexto cultural en que se produzca, de la misma forma que en los estados capitalistas democráticos refleja la ideología capitalista. Otro ejemplo sería la publicidad comercial durante la Guerra Civil Española como reflejo ideológico del bando nacional (Rodríguez Centeno, 2004). Pero más allá de este tipo de reflejos ideológicos, lo verdaderamente interesante para el estudio de la publicidad desde un punto de vista propagandístico sería el uso deliberado de los anuncios con fines ideológicos pro-poder, y no exclusivamente comerciales; en otras palabras, lo interesante sería la instrumentalización o el uso propagandístico de la publicidad. La publicidad bien puede reflejar una ideología pro-poder, pero eso es muy distinto a tener la intención de propagar una ideología pro-poder.

De la idea de que los anuncios comerciales puedan usarse con fines propagandísticos no debe concluirse que la publicidad es propaganda, pues sería lo mismo que concluir que el arte o la literatura son propaganda debido a que en ocasiones se han utilizado propagandísticamente. En otras palabras, la posibilidad de que una instancia de poder emplee la publicidad con fines ideológicos no supone necesariamente que toda la publicidad sea intrínsecamente propaganda; lo que ocurriría es que se estaría subordinando la intención y el contenido comerciales a una intención de propaganda. Las siguientes palabras de 1923 de Vladimir Maiakovsky (quien en 1908 se afilió al partido bolchevique, donde trabajó como propagandista) podrían relacionarse con esa subordinación de lo comercial a lo propagandístico:

\begin{abstract}
Conocemos el maravilloso poder de la agitación... La burguesía conoce el poder de la publicidad. La publicidad es agitación industrial, comercial. Ningún negocio, ni siquiera el más seguro y fiable, puede mantenerse sin publicidad. La publicidad es el arma surgida de la competencia... No podemos dejar esa arma, esa agitación en favor del comercio, en manos de Ios Nepmen, en manos de los burgueses extranjeros que comercian aquí. Todo, en la URSS, debe funcionar para bien del proletariado. ¡Prestemos alguna atención a la publicidad! (Maiakovsky, citado en Chernevich, 1989: 23).
\end{abstract}

Maiakovsky no está negando la naturaleza económica de la publicidad ("La publicidad es agitación industrial, comercial"); lo que está proponiendo es la instrumentalización soviética de la publicidad. Esto confirmaría nuestra hipótesis acerca de la instrumentalización propagandística de la publicidad. También sería el caso de la cartelería turística de Mariano Bertuchi sobre Marruecos: publicidad con posible intención propagandística, dados los vínculos del artista con el poder (Rey, 2004). Otro ejemplo sería el caso del War Advertising Council estadounidense, establecido en el contexto de la 2a ${ }^{\underline{a}}$ Guerra Mundial por la industria publicitaria con fines que mezclaban lo propagandístico y las relaciones públicas de dicha 
industria (Yesil, 2004); de hecho, el War Advertising Council sugirió directrices propagandísticas que influyeron en los anuncios (Yesil, 2004: 110).

En resumen, en el análisis de la publicidad desde un punto de vista propagandístico habría que dejar aparte los niveles de la creatividad y la estrategia (que son puramente publicitarios), y centrarse en un nivel superior, referido exclusivamente a las ideologías propoder: ¿hasta qué punto el contenido de un mensaje publicitario refuerza la ideología y el poder? O, en el caso de que exista una intención ideológica pro-poder clara, ¿en qué medida actúa como propaganda? En definitiva, se trataría de analizar hasta qué punto la publicidad actúa de manera deliberada como un fenómeno socialmente estructurante. Otro ámbito de análisis que surgiría en este contexto sería saber en qué medida la publicidad se desubstancializaría, mitigándose su intención comercial y subordinándose a la intención propagandística; en otras palabras, hasta qué punto dejaría de ser publicidad y se convertiría en propaganda.

\section{El enfoque histórico: las condiciones genéticas de la publicidad y la propaganda}

Consideramos que, una vez expuesto nuestro punto de vista, la perspectiva histórica puede reforzar la hipótesis conceptual. La cuestión es: ¿ofrecen la historia de la propaganda y la historia de la publicidad indicios para establecer una distinción teórica entre ambas según el criterio intencional propuesto?

\subsection{Puntos de convergencia histórica}

Al igual que ocurre entre la propaganda y las relaciones públicas, la propaganda presenta ciertas relaciones históricas con la publicidad ${ }^{8}$. Eulalio Ferrer señala que, históricamente, la publicidad nació de la propaganda: lo que fue promoción de hombres e ideas se transforma en propaganda de cosas, en publicidad. Las técnicas de persuasión, frases hechas, medias verdades o técnicas como la exageración, la glorificación y la sensación de felicidad, son recursos que, según Ferrer, fueron tomados de la propaganda por parte de los publicistas comerciales (Ferrer, 1992: 17). Curiosamente, a finales del siglo XIX y principios del XX la situación se invierte: la propaganda científica de la Primera Guerra Mundial descubrió en los avances de la publicidad decimonónica tardía nuevas formas de expresión, que fueron abiertamente explotadas en Estados Unidos por el Comité Creel (de hecho, el propio Creel escribió un libro tras el conflicto titulado How we advertised America). Para Ferrer, el giro irreversible de la propaganda a la publicidad

se manifiesta muy tenuemente durante la I Guerra Mundial [...] y se activa, como una elaboración superada, después de la II [...]; de una manera más concreta a partir de los años 50. En ambas guerras, la publicidad comenzó a actuar en función de la propaganda, pero dentro de los perfiles y moldes de ésta. Las campañas y mensajes patrióticos obedecían a las

\footnotetext{
8 Para un interesante análisis de las analogías y relaciones genéticas entre publicidad comercial y propaganda política, véase Ayala, 1972a y 1972b.
} 
consignas y fines de la propaganda [...], pero con técnicas publicitarias, cada vez más acentuadas, de producción y proyección (1992: 251).

Según Jowett y O'Donnell, "many of the techniques developed to persuade customers to purchase products were later adopted by other propagandists" (1986: 62). Pizarroso, por su parte, ve una relación de mutua influencia entre propaganda política y publicidad comercial:

\begin{abstract}
Plantearse [...] la relación entre propaganda política y publicidad comercial en el siglo XX es como plantearse el problema del huevo o la gallina. No cabe duda de que la propaganda política recoge numerosas técnicas desarrolladas previamente por la publicidad comercial. Pero ésta, que es necesariamente conformista con una situación social y política dada, se adapta al gusto, a las imágenes y símbolos creados por un régimen [...] previamente. Con ello refuerza además la acción persuasiva de la propaganda política (Pizarroso, 1993: 326).
\end{abstract}

\title{
8.2. Diferencias históricas
}

Junto a los puntos de contacto histórico (que, como puede comprobarse, son sobre todo de naturaleza técnica), propaganda y publicidad presentan diferencias también históricas que, siguiendo nuestra hipótesis, sostienen la distinción conceptual de ambos fenómenos.

El carácter transhistórico de la propaganda es un factor relevante al respecto: cuando la publicidad (en el sentido en que la entendemos actualmente, a partir de la Revolución Industrial) estaba fraguándose históricamente, la propaganda ya tenía siglos de historia. En este contexto, el problema que presenta la publicidad es que sus causas no tienen el mismo carácter transhistórico que la propaganda: su configuración definitiva no tuvo lugar hasta el desarrollo de la economía capitalista de mercado en el siglo XIX. Y a esa altura de la Historia, la propaganda ya tenía una larguísima tradición. Por ejemplo, frente al carácter disperso y asistemático de la proto-publicidad en el mundo antiguo -incluido el grecorromano-, la propaganda denotaba ya en ese mundo un carácter crucial y deliberado por parte del poder. Como afirma Eguizábal Maza en Historia de la publicidad:

\begin{abstract}
Uno de los elementos que más llama la atención, en cuanto a comunicación pública, en la Roma antigua, es la abundancia, y a veces la virulencia, de los mensajes sobre temas políticos y electorales. Pero no son sólo anuncios o pintadas, ni mucho menos, los que expresan el sentimiento político de la vida romana. Los arcos triunfales y las columnas conmemorativas, los desfiles, la construcción de muchos edificios públicos, lujosos y perfectamente inútiles, de anfiteatros, etc., eran también las manifestaciones del poder, de quien quería congraciarse con su pueblo, recordarle su grandeza o simplemente impresionarle. El poder establecido tenía sus símbolos, las [á]guilas imperiales, las siglas SPQR (Senatus Populusque Romanus), que eran reconocidos a I[o] largo y ancho del vasto Imperio Romano (1998: 33).
\end{abstract}

Es decir, frente a la fragmentaria actividad proto-publicitaria del mundo antiguo, en ese mismo mundo ya existía una actividad propagandística institucionalizada, dado que también existía un poder institucionalizado. El explicans de la propaganda es, pues, mucho más universal y transhistórico que el de la publicidad, que, en sentido estricto, está sujeta a la existencia del comercio y de una economía de mercado. 
La transhistoricidad de la propaganda implica que su causa generadora es distinta a la de la publicidad, dado que esta última está más sujeta a la historia, y, por consiguiente, sus factores genéticos no pueden tener la misma universalidad que los de la propaganda. En otras palabras, las causas generadoras de la propaganda y la publicidad son distintas y, por lo tanto, pueden considerarse fenómenos distintos. Como decíamos en un trabajo anterior (Pineda, 2006: 109), la propaganda es "una forma comunicacional de manifestación del poder, del mismo modo en que la publicidad comercial es una forma comunicacional de manifestación de la economía capitalista, o que la literatura es una forma comunicacional de manifestación de necesidades expresivas humanas de tipo estético". Una instancia de poder organizado genera propaganda cuando se comunica, pero no puede aplicarse la misma ley a la generación de publicidad.

Mientras que la propaganda es algo consustancial al poder de todos los tiempos (poder político, religioso o de cualquier tipo), la publicidad es básicamente una forma de comunicación comercial que surgió en el sistema de producción capitalista cuando la oferta superó a la demanda. Como señala José Ramón Sánchez Guzmán (Breve Historia de la Publicidad) en relación a la economía del siglo XIX (1989a: 38-39):

\begin{abstract}
Librecambio y competencia rigen la nueva situación económica y con ello comienza a estimularse la actividad publicitaria. El impacto de la Revolución industrial constituirá un impulso adicional, al permitir la producción de grandes cantidades de mercancías más fáciles de fabricar que de vender y al establecer la producción y distribución en masa basándose en la ruptura de la relación personal entre productor y consumidor que hace inevitable el recurso de la publicidad.

En efecto, la comunicación entre el productor y el consumidor de una mercancía está determinada por las relaciones sociales y técnicas que se dan en toda producción. En una economía precapitalista, el productor fabrica la mercancía en función del pedido del futuro consumidor, de tal forma que el artesano y el cliente se encuentran unidos por una comunicación bidireccional. Es posible también en este tipo de economía que el productor, atendiendo a una incipiente demanda, fabrique la mercancía sin pedido previo y, entonces, intentará comunicar su existencia mediante algún procedimiento como, por ejemplo, «el grito», en el que algunos autores han visto como el antecedente de la publicidad. Pero, con todo, sigue siendo una comunicación directa.
\end{abstract}

Según observa Raúl Eguizábal en su Historia de la publicidad: “La publicidad es una actividad empresarial de carácter comunicativo que se manifiesta con la existencia de esos mensajes que llamamos anuncios" (1998: 199). La condición, pues, es que haya empresas para que haya publicidad; una condición que la propaganda no precisa, pues su alcance es más universal. Las empresas pueden hacer propaganda, pero también pueden hacerla los emperadores, los partidos políticos, las iglesias, los grupos de presión, los ejércitos, etc.

No es casual que la publicidad se haya visto como una forma de la comunicación comercial (García Uceda, 1997: 20-21; Sánchez Guzmán, 1989b: 379-380): lo comercial no supone únicamente la finalidad básica de la mayoría de esfuerzos publicitarios, sino también su génesis comunicativa e histórica. $Y$ es una finalidad que no puede erradicarse ni siquiera en los contextos más proclives a la ideologización y la propaganda. Según Bilge Yesil, en su análisis de material propagandístico y material publicitario dirigido a mujeres durante la Segunda Guerra Mundial, la necesidad de mantener la feminidad era un mensaje comunicado 
a las mujeres en la propaganda y en la publicidad, pero, mientras que las agencias propagandísticas tenían una preocupación ideológica, los anunciantes tenían motivos propios, como las oportunidades de mercado (Yesil, 2004). Un mismo contenido ideológico, pero distintas intenciones:

\begin{abstract}
The emphasis on beauty and womanliness was a prevalent theme in both propaganda and advertising discourse. Although they had distinct interests in promoting these values-maintain traditional gender boundaries versus sell products-propaganda agencies and advertising industry nevertheless conveyed the same message: beauty and femininity should not be compromised (Yesil, 2004: 113).
\end{abstract}

En este contexto, podría afirmarse que, aunque la publicidad se ponga al servicio de fines propagandísticos, persiste siempre, latente, su intención comercial.

A diferencia de la publicidad, la existencia del capitalismo no es una condición de existencia para la propaganda: esta última podría surgir en sistemas económicos regidos por instancias de poder antimercado. El caso de la URSS puede ser ilustrativo al respecto: aunque durante la década de 1920 existió publicidad en Rusia (Eguizábal Maza, 1998: 299-303), el fin de la Nueva Política Económica modificó la situación. Como señala Eguizábal Maza (1998: 301): “el entorno creado por la Nueva Política Económica (NEP) urgió al Estado a anunciar sus propios productos en competencia con los productos de las empresas privadas. El Estado se convirtió en un poderoso anunciante en el campo económico". Eguizábal Maza también señala (1998: 303): “No podemos saber hasta dónde hubiese llegado la publicidad soviética, pues el final de la NEP (1927) acabó con la publicidad y la pequeña libertad económica que la habían justificado". Sin embargo, y a diferencia de esta experiencia publicitaria, la labor propagandística soviética duró décadas. Por ejemplo: “El dicho de Lenin de que «la prensa es el arma más poderosa del Partido» es todavía la base de la actitud soviética hacia sus periódicos", se lee en un dossier documental publicado en 1975 en la Revista española de la opinión pública. "Su propósito primario es propagar la doctrina del partido comunista y ayudar al partido a conseguir sus objetivos en la sociedad, educando al pueblo" (Valentín Isidro, 1975: 242).

En definitiva, la historia evidencia que los sistemas de propaganda no van necesariamente en paralelo con sistemas publicitarios. En la Edad Media, la desaparición de una proto-publicidad no fue obstáculo para que existiera propaganda de la Iglesia y la nobleza. Tanto el capitalismo estadounidense como el sistema soviético desarrollaron sistemas de propaganda formidables y fácilmente reconocibles como tales. ¿Es casual que en la Unión Soviética apenas se produjese publicidad comercial? No lo es, porque responde a una diferencia esencial entre fenómenos comunicativos distintos. A diferencia de la propaganda, que tiene un explicans universal, la publicidad está delimitada tanto desde el punto de vista histórico como desde el económico o el sociológico. La publicidad está sujeta a un modo de producción muy determinado; si el capitalismo se transforma o desaparece, la publicidad se transformará o desaparecerá. Pero mientras existan instancias de poder que decidan comunicarse con quienes están sujetos a su poder, la propaganda estará ahí. 


\section{Conclusiones}

La identificación de propaganda y publicidad es una cuestión que plantea más interrogantes teóricos que explicaciones satisfactorias. Ante ello, hemos planteado la hipótesis de que propaganda y publicidad son dos manifestaciones comunicativas esencialmente distintas si las consideramos desde una perspectiva intencional. Sus vínculos se reducen a aspectos que, desde un punto de vista científico y conceptual -que no descriptivo-, son en su mayoría irrelevantes.

Junto a ciertos aspectos procedimentales, mediáticos y contextuales, la publicidad y la propaganda tienen una visión antropológica y psicológica similar del receptor. También ambas intentan influir en favor del interés del emisor; incluso, pueden compartir un contenido ideológico. Sin embargo, los fines que persiguen, el objeto de su comunicación, las define y distingue; y todo ello condiciona que sus contenidos sean en su mayoría distintos. Todo lo cual no obsta, evidentemente, para que la publicidad pueda ser instrumentalizada propagandísticamente, o para que existan contenidos ideológicos en la publicidad que actúen como un reflejo cultural en sintonía con las necesidades del poder.

Lo importante es que más allá de las designaciones terminológicas propaganda y publicidad se puedan distinguir con claridad dos conceptos (explicables por causas histórico-genéticas distintas y movidos por intenciones distintas), de la misma manera que podemos distinguir comunicaciones destinadas a informarnos sobre el clima o a provocarnos una experiencia estética. La publicidad responde a la intención de las empresas comerciales de vender sus productos y servicios, y/o implantar sus marcas en la sociedad. $Y$ es en ese terreno donde deben dilucidarse sus diferencias con las manifestaciones propagandísticas generadas por las instancias de poder. En definitiva, establecer la diferencia entre propaganda y publicidad en función de un criterio intencional implica, desde un punto de vista comunicacional, desplazar la atención desde el mensaje o el receptor hacia el emisor. 


\section{REFERENCI AS BI BLI OGRÁFI CAS}

Ayala, Francisco (1972a): "Propaganda y democracia", en Hoy ya es ayer, Madrid, Moneda y Crédito, pp. 193-200.

Ayala, Francisco (1972b): “Propaganda y política”, en Hoy ya es ayer, Madrid, Moneda y Crédito, pp. 200-229.

Bernays, Edward L. (1998): Cristalizando la Opinión Pública. Traducción de Ernesto Gómez Cereijo, Barcelona, Gestión 2000.

BASSAT, Luis (2004): El libro rojo de la publicidad. Barcelona, Random House Mondadori.

BORI, Rafael, y GARDó, José (1935): Tratado completo de publicidad y propaganda. Biblioteca del Hombre de Negocios Moderno, I-II, Barcelona, José Montesó Editor.

Chapman Brown, Harold (1929): “Advertising and Propaganda: A Study in the Ethics of Social Control", en International Journal of Ethics, Vol. 40, No. 1. (Oct., 1929), pp. 39-55.

Chernevich, Elena (1989): “Introducción” a Mikhail ANIKST y Elena CHERNeVICH: Diseño gráfico soviético. Años 20. Edición y diseño por Mikhail Anikst. Introducción y textos de Elena Chernevich. Documentación de N. Baburina. Versión castellana de Emili Olcina i Aya, Barcelona, Gustavo Gili, pp. 6-29.

Cogswell, David (1997): "History is Not Over. Mechanisms Exist to Change the System. A Conversation with Noam Chomsky", April 18, 1997, en http://www.hal-pc.org/ clyndes/Chomsky.html (consultado: 12/06/2007).

DOMENACH, Jean-Marie (1986): La propaganda política. Editorial Universitaria de Buenos Aires.

Dоов, Leonard W. (1966): Public Opinion and Propaganda. 2a edición, Connecticut, Archon Books.

DURANDIN, Guy (1990): La mentira en la propaganda política y en la publicidad. Traducción de Irene Agoff, Barcelona, Paidós.

EguizÁBAl MAZA, Raúl (1998): Historia de la publicidad. Madrid, Eresma \& Celeste Ediciones.

FERNÁNDEZ SOUTO, Ana Belén (2006): “Las relaciones públicas como elemento tangencial entre la publicidad, propaganda, información y otras áreas de la comunicación", en Revista Mexicana de Ciencias Políticas y Sociales, eneroabril, año/vol. XLVIII, número 196, pp. 159-170.

Ferrer, Eulalio (1992): De la lucha de clases a la lucha de frases. Madrid, El País / Aguilar. 
FIgUeROA SORIA, José Guadalupe (1998): “Publicidad y propaganda. Una mirada desde México", en Revista Universitaria de Comunicación Política, núm. 1, pp. 149-159.

García UCEDA, Mariola (1997): Las claves de la publicidad. 2a Edición Revisada, Madrid, ESIC.

GARRIDO, Rafael (2002): “¿Las Marcas diferencian?”, en Investigación y Marketing, Núm. 76, Septiembre, pp. 9-13.

GonZÁLEZ LoBo, Ma Ángeles (1998): Curso de Publicidad. Madrid, Eresma \& Celeste Ediciones.

GonzÁlez MARTín, Juan Antonio (1996): Teoría general de la publicidad. México D. F. y Madrid, Fondo de Cultura Económica.

HAAS, C. R. (1966): Teoría, técnica y práctica de la publicidad. Tercera edición. Versión española realizada por Rosalía VÁzQuEZ, Madrid, Rialp.

Herreros Arconada, Mario (1989): Teoría y técnica de la propaganda electoral (formas publicitarias). Barcelona, PPU.

Herreros Arconada, Mario (1999): "Teoría de la publicidad", en José Luis Arceo VACAS (Director): Tratado de publicidad y relaciones públicas. Madrid, ICIE, Universidad Complutense de Madrid, pp. 409-466.

HORKHEIMER, Max, y AdORNo, Theodor W. (1998): Dialéctica de la Ilustración. Introducción y traducción de Juan José Sánchez, Madrid, Trotta.

J OWETT, Garth S. (1987): “Propaganda and Communication: The Re-emergence of a Research Tradition", en Journal of Communication, 37:1, Winter, pp. 97114.

JoWETT, Garth S., y O'DONNeLL, Victoria (1986): Propaganda and Persuasion. Newbury Park / London / New Delhi, Sage Publications.

KATZ, Elihu, y LAZARSFELD, Paul F. (1979): La influencia personal. Traducción de Alberto Pérez Álvarez, Barcelona, Editorial Hispano Europea.

LASSWELL, Harold D., CASEY, Ralph D., y SMITH, Bruce Lannes (eds.) (1969): Propaganda and Promotional Activities. An Annotated Bibliography. The University of Chicago Press.

Musitu, Gonzalo, y CASTILlo, Rafael (1982): Publicidad y Propaganda. Valencia, NAU llibres.

OCAÑA, Fernando (2005): "Introducción. Veinte ideas sobre publicidad", en Jorge David FERNÁNDEZ GómEZ (coordinador): Aproximación a la Estructura de la Publicidad, Sevilla, Comunicación Social Ediciones y Publicaciones, pp. 2633.

ORTEGA, Enrique (1997): La comunicación publicitaria. Madrid, Pirámide. 
PIGNOTTI, Lamberto (1976): La supernada. Ideología y lenguaje de la publicidad. Traducción: Joaquín Espinosa Carbonell, Valencia, Fernando Torres Editor.

Pineda CACHero, Antonio (2005): Elementos para una teoría comunicacional de la propaganda. Tesis Doctoral dirigida por Manuel Ángel VÁzQuez Medel y Adrián HUICI MódenES, Sevilla, Departamento de Comunicación Audiovisual y Publicidad y Literatura de la Universidad de Sevilla.

Pineda CAChero, Antonio (2006): Elementos para una teoría comunicacional de la propaganda. Sevilla, Alfar.

PizARRoso, Alejandro (1993): Historia de la propaganda. 2a a edición, ampliada, Madrid, Eudema.

Qualter, Terence H. (1994): Publicidad y democracia en la sociedad de masas. Traducción de Pilar Vázquez Mota, Barcelona, Paidós.

REY, Juan (2004): “La cartelería turística como propaganda de la Administración Colonial Española. El caso de Mariano Bertuchi: La cara amable de Marruecos", en Adrián Huici Módenes \& Antonio Pineda Cachero (coords.): Propaganda y Comunicación, Sevilla, Comunicación Social Ediciones y Publicaciones, pp. 32-49.

ReYZÁBAL, María Victoria (1999): Propaganda y manipulación. Madrid, Acento.

Rodríguez Centeno, Juan Carlos (2002): “Comunicación en tiempos de guerra. Aproximación teórica a los mensajes y los medios: ideología y simbología/propaganda y publicidad", en Comunicación. Revista Internacional de Comunicación Audiovisual, Publicidad y Estudios Culturales, № 1 (Imagen, cultura y comunicación. Homenaje al Profesor Diego Coronado e Hijón), pp. 117-129.

Rodríguez Centeno, Juan Carlos (2004): “La publicidad comercial al servicio de la propaganda política: el caso de la Guerra Civil Española", en Adrián HulCl Módenes \& Antonio Pineda CaChero (coords.): Propaganda y Comunicación. Sevilla, Comunicación Social Ediciones y Publicaciones, pp. 119-136.

SÁnCHeZ GuZmán, José Ramón (1989a): Breve Historia de la Publicidad. Madrid, Ciencia 3.

SÁNCHEZ GuZMÁn, José Ramón $\left(1989 b^{9}\right)$ : Marketing Comunicación. Ciencia 3 Distribución.

SANI, Giacomo (1983): "propaganda.", en Norberto BoBBIO y Nicola MATTEUCCI (dirs.): Diccionario de política, vol. II, Madrid, Siglo XXI Editores, pp. 13331336.

\footnotetext{
${ }^{9}$ Fecha del Depósito legal.
} 
SCHILLER, Herbert I. (1987): Los manipuladores de cerebros. 2a edición. Traducción: Eduardo Goligorsky, Barcelona, Gedisa.

VALENTín ISIDRO, J. M. (1975): “Los medios de comunicación de masas en la Unión Soviética, China Continental y Japón", en Revista española de la opinión pública número 39, enero - marzo, pp. 241-254.

VÁZQUEZ, I gnacio, y ALDEA, Santiago (1991): Estrategia y manipulación del lenguaje. Zaragoza, Universidad de Zaragoza.

VERES CORTÉs, Luis (1999): “De propaganda y publicidad: notas acerca de una distinción", en Comunicación y estudios universitarios, Núm. 9, pp. 133-140.

Villafañe, Justo (2004): “Presentación” a Justo Villafañe (Dirección); Eduardo Moreno Amador, y Aurora Pimentel Igea: El Estado de la Publicidad y el Corporate en España y Latinoamérica. La empresa dialogante. Madrid, Pirámide, pp. 9-10.

Wells, William, BurnetT, John, y Moriarty, Sandra (1996): Publicidad. Principios y prácticas. Tercera Edición. Traducción: Concepción Verania de Parres Cárdenas. Revisión técnica: Marcela Benassini Félix, Naucalpan de Juárez, Edo. de México, Prentice-Hall Hispanoamericana, S.A.

YESIL, Bilge (2004): “'Who Said this is a Man's War?': propaganda, advertising discourse and the representation of war worker women during the Second World War", en Media History, Vol. 10, No. 2, pp. 103-117.

[Recibido: 30-10-2007. Aceptado: 30-11-2007] 